\title{
Decreased vascular endothelial growth factor response to acute hypoglycemia in type 2 diabetic patients with hypoglycemic coma
}

Francisco Arnalich ${ }^{1}$, Maria Constanza Maldifassi ${ }^{2}$, Gema Atienza $^{2}$, Enrique Ciria ${ }^{1}$, Angustias Quesada ${ }^{1}$, José Luis Cedillo ${ }^{2}$, Jaime Renart ${ }^{3}$, Rosa Codoceo ${ }^{4}$, Rafael Herruzo $^{5}$, Carmen Montiel ${ }^{2}$.

${ }^{1}$ Emergency Medicine Service, Internal Medicine Department, Hospital Universitario La Paz. IdiPAZ. Paseo de la Castellana 261.28046 Madrid, Spain

${ }^{2}$ Department of Pharmacology and Therapy, Facultad de Medicina Universidad Autónoma de Madrid. IdiPAZ. Arzobispo Morcillo, 4. 28029 Madrid, Spain.

${ }^{3}$ Institute of Biomedical Research "Alberto Sols". Consejo Superior de Investigaciones Científicas. Arturo Duperier, 4. 28029 Madrid, Spain.

${ }^{4}$ Clinical Biochemistry Service, Hospital Universitario La Paz. IdiPAZ. Paseo de la Castellana 261.28046 Madrid, Spain

${ }^{5}$ Preventive Medicine Service and Research Unit, Hospital Universitario La Paz. IdiPAZ. Paseo de la Castellana 261.28046 Madrid, Spain.

Francisco Arnalich (farnalich.hulp@salud.madrid.org)

Maria Constanza Maldifassi (mariaconstanza.maldifass@uam.es)

Gema Atienza (gema.atienza@uam.es)

Enrique Ciria (eciria.hulp@salud.madrid.org)

Angustias Quesada (aquesada.hulp@salud.madrid.org)

José Luis Cedillo (jose_cedillo_mireles@ hotmail.com)

Jaime Renart (jrenart@iib.uam.es)

Rosa Codoceo (rcodoceo.hulp@ salud.madrid.org)

Rafael Herruzo (afael.herruzo@uam.es)

Carmen Montiel (carmen.montiel@uam.es)

\section{Corresponding author:}

Francisco Arnalich. Emergency Medicine Service, Internal Medicine Department.Hospital Universitario La Paz. Paseo de la Castellana 261, 28046 Madrid, Spain.

Tel: +34 91727 7126; Fax: +34 91727 7104. E-mail: farnalich.hulp@salud.madrid.org 


\begin{abstract}
Introduction: Plasma vascular endothelial growth factor (VEGF) was shown to increase during acute hypoglycemia and could mediate rapid adaptation of the brain. In this study we examined the neuroendocrine response in patients with type 2 diabetes mellitus (T2DM) in hypoglycemic coma or with acute neuroglycopenic symptoms.
\end{abstract}

Methods: We prospectively studied 135 consecutive T2DM patients admitted for severe hypoglycemia during a 2-year period. We collected clinical variables and measured plasma concentrations of VEGF, epinephrine, norepinephrine, cortisol and growth hormone at admission and 30 min afterwards.

Results: 32 patients developed hypoglycemic coma and 103 did not lose consciousness. Median plasma VEGF level of coma patients was 3.1-fold lower at baseline than that of non-coma patients, and even 5.3-fold lower 30 min afterwards. Plasma epinephrine concentration was significantly lower just at baseline in coma patients. On the contrary, there were no differences in concentrations of the other hormones. Multivariate logistic regression analysis showed that VEGF concentration (OR 0.68; CI 0.51-0.95) was a protective factor against the development of coma.

Conclusions: VEGF and epinephrine responses to acute hypoglycemia are reduced in T2DM patients who develop hypoglycemic coma. An increased plasma VEGF concentration appeared to be a protective factor against the development of hypoglycemic coma.

Keywords: Vascular endothelial growth factor; type 2 diabetic patients; symptomatic hypoglycemia; hypoglycemic coma; hypoglycemia unawareness; plasma concentrations. 


\section{Introduction}

Symptoms of hypoglycemia are typically characterized as neurogenic and neuroglycopenic, and both types occur at about the same glycemic threshold, equal to approximately $3.0 \mathrm{mmol} / \mathrm{l}(54 \mathrm{mg} / \mathrm{dl})$ [1,2]. Neuroglycopenia causes a rapid impairment of cerebral function and induces different symptoms in different individuals that, if not promptly treated, ultimately lead to coma, or even death [3]. In two retrospective studies of elderly patients admitted to emergency departments with blood glucose concentrations under $2.8 \mathrm{mmol} / \mathrm{l}$, almost all patients had neuroglycopenic symptoms and over $45 \%$ presented loss of consciousness $[4,5]$. Acute hypoglycemia not only induces cognitive dysfunction but also impairs autonomic cardiovascular function [6] and can precipitate an acute coronary syndrome leading to myocardial infarction and death [7]. In a prospective study by our group 3 out of 89 patients with cardiac arrest had concurrent myocardial infarction and severe iatrogenic hypoglycemia [8].

During acute hypoglycemia, glucagon and epinephrine are secreted as glucose levels drop slightly below the physiologic range, at approximately $3.8 \mathrm{mmol} / \mathrm{l}(68 \mathrm{mg} / \mathrm{dl})$, and the three efferent components of the autonomic nervous system, the adrenomedullary, sympathetic neural, and parasympathetic neural responses become activated [9, 10]. Secretion of GH and cortisol, both of which limit glucose utilization by insulin-sensitive tissues, occurs at a lower plasma glucose concentration range between 3.7-3.2 mmol/l, but these hormones appear to play a minor role in glucose autoregulation.

One of the known effects of VEGF, a key regulator of both angiogenesis and vasculogenesis [11], is the enhancement and translocation of the glucose transporter 1 (GLUT1) to the plasma membrane of endothelial cells at the blood-brain barrier (BBB) [11] and in retinal endothelial cells [12]. Furthermore, VEGF induces endothelial 
fenestration and increases vascular permeability of the BBB [13] Both mechanisms, upregulation of GLUT1 and rise of BBB permeability, can enhance brain glucose supply.

Under normal conditions, GLUT 1-mediated BBB glucose transport is not limiting for glucose metabolism in the brain. However, when blood glucose drops below 3,0 $\mathrm{mmol} / \mathrm{l}$, the effect of VEGF on GLUT1 expression and translocation at the BBB may be critical in maintaining brain glucose uptake [14].

Plasma VEGF has been shown to increase in response to hypoglycemia in vivo during hypoglycemia and it was proposed that VEGF could mediate rapid adaptation of the brain to neuroglycopenia [15]. However, no study has yet addressed the counterregulatory response of VEGF and other hormones in T2DM patients with severe symptomatic hypoglycemia or coma. The purpose of this study is to examine the neuroendocrine response in diabetic patients with hypoglycemic coma or acute neuroglycopenic symptoms at the time of the first encounter with medical assistance and 30 min afterwards, and to investigate possible associations with any concomitant risk factor for hypoglycemia.

\section{Material and methods:}

\subsection{Patients and setting:}

Between March 2005 and June 2007, 194 consecutive patients with T2DM were admitted to the emergency department (ED) for severe hypoglycemia, which was defined according to the recommended classification of the American Diabetes Association Workgroup on Hypoglycemia [16]. Of these, 152 patients were considered for enrollment into this study because they met the following inclusion criteria: 1) a measured plasma glucose concentration $\leq 2.8 \mathrm{mmol} / \mathrm{l}(50 \mathrm{mg} / \mathrm{dl}) ; 2)$ a documented 
transient loss of consciousness at arrival in the ED, or other major neuroglycopenic symptoms. Seventeen patients presented one of more of the following exclusion criteria: 1) T2DM and other potential causes of coma (e.g. hepatic coma, uremic coma, stroke, septic shock), 2) all forms of secondary diabetes, 3) morbid obesity (BMI >45), 4) antecedents of alcoholism or epileptic attacks, 5) chronic renal failure treated by hemodialysis, severe liver disease, or neoplastic diseases, 6) incomplete ED medical records, and 7) patients or their families refused to participate. These 17 patients were excluded from analysis. Therefore, the final cohort included 135 consecutive patients with symptomatic severe hypoglycemia and rapid impairment of mental function at the time of admission to the ED. For analysis, patients were divided into 2 groups: The coma group consisted of 32 patients with hypoglycemic coma (defined as a prolonged loss of consciousness without responsiveness to vigorous calling and/or pain, and/or by a Glasgow Coma Scale score equal to or below 8 points, and a complete recovery after resolution of hypoglycemia). The non-coma group consisted of 103 patients who maintain a normal conscious level but experienced one or more of the following neuroglycopenic symptoms: warmth, weakness, difficulty in thinking, difficulty speaking, confusion, tiredness, drowsiness, uncoordination. In 35 patients these symptoms persisted for at least 30 min after restoration of normoglycemia and they were considered as a different subgroup.

Institutional review board approval was obtained for this study, which was carried out according to the Declaration of Helsinki after obtaining written informed consent from all subjects or their relatives. The following patient data were collected from hospital charts: age, gender, duration of T2DM (years), first plasma glucose measurement and subsequent measurements, the presence or the absence of loss of consciousness 
(Glasgow Coma Scale), presence of neuroglycopenic symptoms, duration of hypoglycemia (from first measurement to stable plasma glucose concentration greater than $5.0 \mathrm{mmol} / \mathrm{l}$ ), laboratory test values (white blood cell count, hemoglobin, aspartate transaminase, blood urea nitrogen, serum creatinine, hemoglobin A1c (HbA1c). The estimated glomerular filtration rate (eGFR) was calculated from the serum creatinine level [17]. We also recorded predisposing factors for hypoglycemia, current diabetes therapy, use of potentiating drugs for hypoglycemia, polypharmacy (defined as more than 5 medications). The criteria used to identify comorbidities and complications of diabetes, and to diagnose acute bacterial infection are indicated as Supplementary Data in the Supplementary File.

Before discharge from hospital, all patients were asked to recall if they had had episodes of hypoglycemia in the preceding 6 months. Mild hypoglycemia was defined by the ability to have self-treated the episode and severe hypoglycemia as having required external assistance for recovery. All participants completed a questionnaire to assess their awareness of hypoglycemia using the method of Gold et al. [18]. An index of selfestimated awareness of hypoglycemia was derived from the patient's answers and scored on a scale of 1-7 (1=always aware, 7=never aware). Subjects were asked to assess whether symptoms of hypoglycemia had increased, decreased, or were unaltered over time. Those reporting diminution in symptom intensity and/or a score of 4 out of 7 or more on the awareness scale were classified as having impaired awareness of hypoglycemia [18]. After discharge, all participants were followed twice monthly at the outpatient medical clinic, and treatment target was relaxed to maintaining a glycemic level between 125 and $150 \mathrm{mg} / \mathrm{dl}$. They performed capillary blood glucose measurements using their own blood glucose meters, three times daily or when 
experiencing any symptoms attributable to hypoglycemia, and completed a questionnaire to assess their awareness of hypoglycemia whenever the measured blood glucose values were less than $60 \mathrm{mg} / \mathrm{dl}$. Throughout the 3-month follow-up period, no patient experienced further episodes of severe hypoglycemia.

The main outcome measure was the development of hypoglycemic coma within the first 30 min of admission for severe hypoglycemia diagnosed in the ED.

2.2 Blood sampling and processing:

A $10 \mathrm{ml}$ blood sample was taken from the antecubital vein of each patient at entry in the emergency room, and $30 \mathrm{~min}$ thereafter. In all participants, a third blood sample was drawn after a 3-month follow-up period of stable blood glucose control. Plasma glucose was measured with a glucose oxidase method (Glucose Analyzer 2; Beckman, Munich, Germany; intra- and interassay $\mathrm{CV}<1.8 \%$ and $<2.6 \%$, respectively). Plasma cortisol and growth hormone concentrations were measured by commercial enzyme-linked immunoassays (DPC Immulite, Los Angeles, CA; intra- and interassay $\mathrm{CV}<8 \%$ ). Plasma epinephrine and norepinephrine were measured by standard high-performance liquid chromatography with electrochemical detection (Chromosystems, Munich, Germany; with interassay CV, $<2.9 \%$, interassay CV $<4.2 \%$ ). Plasma VEGF (isoform VEGF-165) was measured by a sandwich-type-enzyme-linked immunoassay (Quantikine; R\&D Systems Europe, Abingdon, UK), with intra- and interassay CV of $<5 \%$ and $<7 \%$, respectively; the lower detection limit was $9 \mathrm{pg} / \mathrm{ml}$.

\subsection{Statistical analyses:}

Continuous data are presented as the median and interquartile range. Discrete variables are given as counts and percentages. Univariate comparisons of continuous data were 
performed by Mann-Whitney $U$-test, and by Chi-square for categorical variables. The confidence interval $(95 \% \mathrm{CI})$ was determined as an indication of the precision of an estimate of a population value. The odds ratio (OR) was calculated as an estimate of relative risk between two groups on the basis of the development of hypoglycemic coma as outcome. Multivariate logistic regression analysis with stepwise forward selection was used to determine the independent contribution of multiple variables to the main outcome. This model included as explanatory or predictor factors the variables that were suggested in the univariate analysis to be more strongly associated with development of hypoglycemic coma. A $p<0.01$ level was used for the inclusion of the variables in the model. Data were analyzed using SPSS, version 13.0 for Windows (SPSS, Chicago, IL, USA)

\section{Results:}

Clinical characteristics of the 135 patients included in this study are shown in Table 1. Within the first $30 \mathrm{~min}$ of admission, thirty-two patients developed a progressive cognitive impairment ending in a hypoglycemic coma that completely resolved within 90 min of glycemia restoration. The remaining 103 patients did not lose consciousness. An associated cause for hypoglycemia was reported in 103 cases (76.3\%). The most common precipitating events were a low energy intake without change in therapy (71 cases), and acute bacterial infection (20 cases). The final diagnosis of infection types were: pneumonia or lower respiratory tract infection in 11 cases (55\%), acute pyelonephritis 7 cases (35\%), and cholecystitis and cholangitis 2 cases (10\%). A previous episode of severe hypoglycemia and self-reported impaired hypoglycemia awareness was found in $20.7 \%$ and $13.3 \%$, respectively, of patients. The table 1 also compares the main laboratory data the day of admission and at 3 months after hospital 
discharge, when patients returned to our clinic for a follow-up visit. No patient in this study group presented any further severe hypoglycemic event. There was a sharp increase in plasma concentrations of VEGF, epinephrine, norepinephrine, cortisol and $\mathrm{GH}$ at the time of severe hypoglycemia as compared to control values after the followup period.

Table 2 compares clinical data and counter-regulatory hormonal responses to hypoglycemia in the two study groups. Patients presenting a hypoglycemic coma had longer disease duration, they experienced a much higher prevalence of previous severe hypoglycemia episodes (62.5\%) and impaired hypoglycemia awareness (46.9\%) than patients without coma, and they were mostly treated with insulin alone (62.5\%). Except for a higher prevalence of CAD in patients presenting hypoglycemic coma, no statistical difference was observed with respect to other cardiovascular risk factors or comorbidities between the two study groups. Plasma HbA1c concentration, and eGFR were significantly lower in the coma group as compared to the non-coma group. The median glucose concentration at admission was slightly lower in the coma group. The median plasma VGEF level in coma hypoglucemic patients was 3.1-fold lower at baseline than that of patients without coma, and did not increase significantly in the second blood sample taken 30 min afterwards. Plasma epinephrine concentrations were also significantly lower at baseline in comatous patients. On the contrary, there were no differences in concentrations of norepinephrine, cortisol and GH in patients with and without coma. None of the patients had acute hypoxia at admission, which would have decreased circulating VEGF concentrations [19]. No relationship was found between plasma VEGF levels and concentrations of the other counterregulatory hormones. In a univariate analysis, significant risk factors associated with hypoglycemic coma were 
previous severe hypoglycemic episodes, impaired hypoglycemia awareness, duration of hypoglycemia, insulin treatment alone, polypharmacy, renal impairment (eGFR $<60$ $\mathrm{ml} / \mathrm{min}$ per $1.73 \mathrm{~m}^{2}$ ), and the plasma concentrations of VEGF and epinephrine. Eighteen of the 135 patients reported impaired hypoglycemia awareness. They had significantly reduced VEGF and epinephrine responses to severe hypoglycemia as compared to that of patients with intact awareness, but no differences were found in the concentrations of the other hormones (Table 3).

A multivariate analysis by logistic regression to identify factors independently associated with the development of hypoglycemic coma was performed. The following variables were entered: 1) age; 2) sex; 3) diabetes duration; 4) self-reported mild hypoglycemia; 5) antecedent of severe hypoglycemia within the past year; 6) impaired hypoglycemia awareness; 7) underlying precipitating cause of hypoglycemia: low carbohydrate intake, acute bacterial infection, errors in the administration of insulin or hypoglycemic agents; 8) comorbidities: hypertension, obesity, dyslipidemia, congestive heart failure, COPD/emphysema; 9) diabetic complications: CAD, peripheral artery disease, retinopathy; 10) $\mathrm{HbA}_{1 \mathrm{c}}$ values on admission; 11) average value of $\mathrm{HbA}_{1 \mathrm{c}}(\leq 7.0$, or >7.0) over the past year; 12) insulin treatment alone; 13) oral antidiabetic agent therapy; 14) the use of any hypoglycemia-potentiating drugs (benzodiacepines, betablockers, RAS blockers, diuretics, NSAIDS): 15) polypharmacy ( $\geq 5$ prescribed medications); 16) renal impairment (eGFR $<60 \mathrm{ml} / \mathrm{min}$ per $1.73 \mathrm{~m}^{2}$ ); 17) circulating concentrations of each of the following counterregulatory hormones: VEGF, epinephrine, norepinephrine, cortisol and GH. After controlling for age and gender (Table 4), it was found that patients with insulin therapy alone (OR 2.48; CI, 1.68-6.12), antecedent severe hypoglycemia (OR 1.86; CI 1.38-5.42), impaired renal function (OR 
1.73; CI 1.10-4.28) and impaired hypoglycemia awareness (1.21: CI 1.10-3.85) were at risk of hypoglycemic coma. In contrast, increased plasma VEGF concentration (OR 0.68; CI 0.51-0.95) was a protective factor against the development of coma. No other variables were independently associated with it.

\section{Discussion}

This study demonstrates that the responses of two major neuroendocrine factors, specifically VEGF and epinephrine, are impaired in patients with hypoglycemic coma. The median plasma concentrations of epinephrine and VEGF in comatous hypoglycemic patients were 1.9 and 3.1-fold lower, respectively, than those of patients without coma, and even 2.0 and 5.3-fold lower in the second blood sample 30 min after. We did not identify any differences in the responses of norepinephrine, cortisol and GH. Antecedents of previous severe hypoglycemic episodes, self-estimated reduced hypoglycemia awareness, insulin treatment and renal impairment also were important risk factors for hypoglycemic coma.

Acute hypoglycemia induced by hypoglycemic clamps in healthy adults is accompanied by a sharp increase in circulating VEGF concentrations [15, 20, 21]. In 16 healthy men subjected to hypoglycemic clamps lasting 6 h, VEGF concentrations showed a 2.5 -fold increase at a glycemic target of $2.3 \mathrm{mmol} / \mathrm{l}$ and the enhanced VEGF response correlated positively with the preservation of neurocognitive function, as measured with memory performance tests. [15]. Recently, it has been reported that plasma VEGF levels increase during short-term insulin-induced hypoglycemia in patients with type-1 diabetes and there was a weak association between cognitive function and the VEGF 
response [22]. In line with these data, the present study indicates that patients with attenuated VEGF and epinephrine responses to severe hypoglycemia had a greater risk of developing coma or neuroglycopenic symptoms that persisted for at least $30 \mathrm{~min}$ after restoration of normoglycemia. Impaired VEGF response, but not epinephrine response, was independently associated with the development of hypoglycemic coma.

The origin of circulating VEGF in response to hypoglycemia is uncertain, although previous findings indicate that the hypothalamus, pituitary and adrenal gland participate in VEGF production and secretion [23, 24]. Circulating VEGF binds to high affinity receptors that are widely distributed throughout the vascular endothelial cells. The highest density of VEGF receptors has been found in endothelial cells of adult brain capillaries, which support the role of VEGF in sustaining brain glucose uptake under hypoglycemic conditions. Through alternative mRNA splicing, a single gene of VEGF, which is localized on chromosome $6 \mathrm{p} 21.3$, rise to several distinct isoforms which range in length from 121 to 206 amino acid residues. Most VEGF-producing cells appear to express three different isoforms (VEGF-121, VEGF-165, and VEGF-189) [25]. In contrast, VEGF-145 and VEGF-206 are mainly restricted to cells of placental origin [26]. VEGF-165 is the predominant isoform that is freely released from producing cells but a significant fraction remains bound to the cell surface and extracellular matrix, whereas VEGF-121 is a freely diffusible protein and does not bind to the cell surface. It is thought that both isoforms, VEGF-165 and to a lesser extent VEGF-121, enhance glucose transport from blood-stream to neurons during acute severe hypoglycemia.

Although there have been few studies on the neuroendocrine responses to acute hypoglycemia in T2DM patients, it has been reported that T2DM alters the normal counterregulatory response of epinephrine to a given level of hypoglycemia and the 
glycemic threshold for its secretion is shifted to lower plasma glucose concentrations, leading to a situation termed "hypoglycemia-associated autonomic failure" where the adrenergic symptoms of hypoglycemia fail to appear until the blood glucose drops to the lowered threshold that produces the epinephrine release [10]. Repeated hypoglycemic episodes reduce the sympatoadrenal responses to subsequent hypoglycemic episodes in patients with types 1 and 2 diabetes [27]. Others studies have shown that tightening glycemic control in T2DM can reduce the degree of epinephrine response to hypoglycemia [28]. A recent study has demonstrated that 6-month intensive glycemic control with triple oral combination therapy significantly reduces epinephrine responses during hypoglycemia in individuals with T2DM [29]. This change in epinephrine response to hypoglycemia is the result of preceding hypoglycemia, which shifts glycemic thresholds for initiation of counterregulation. There may be a functional change in glucosensing neurons in human brain or an alteration in neurotransmission that results from antecedent hypoglycemia.

In our series, the prevalence of earlier severe hypoglycemic events was significantly higher in patients with hypoglycemic coma (46.9\%) than in those without coma (2.9\%), and the epinephrine response to hypoglycemia was significantly reduced in patients with hypoglycemic coma, most of whom had an antecedent of iatrogenic hypoglycemia. Many alterations in brain signaling or metabolism can blunt the counterregulatory responses to subsequent hypoglycemia. One possibility is that recent hypoglycemia increases glucokinase activity in glucosensing neurons in human brain (arcuate nucleus and ventromedial hypothalamic nucleus), resulting in an increased neuronal glucose metabolism which may lead to a reduced sympathoadrenal response [30]. 
The prevalence of impaired awareness of hypoglycemia in insulin-treated T2DM is about $10 \%$ [31]. In our case series, the risk of hypoglycemic coma was increased 2.4fold in patients with hypoglycemia unawareness compared to patients reporting normal awareness. Among the potential mechanisms contributing to unawareness are regional changes in brain glucose-sensing areas, with associated changes in neurotransmission $[32,33]$. Additionally, there may be an upregulation of glucose transport into the brain. Rodent studies have shown that chronic hypoglycemia increases brain glucose transport and GLUT-1 mRNA and protein expression [34]. Brain glucose concentrations measured by ${ }^{1} \mathrm{H}$ nuclear magnetic resonance spectroscopy were found to be higher in patients with type-1 diabetes and hypoglycemia unawareness than in healthy controls $[35,36]$. One possibility is that these changes in brain glucose transport may be established via release of VEGF. Since repeated hypoglycemic episodes attenuated the hypoglycemia-induced VEGF increase [20], one may expect that patients with repetitive hypoglycemia leading to impaired awareness of hypoglycemia would have reduced VEGF response during severe hypoglycemia or hypoglycemic coma. In keeping with this assumption, the present study has found that patients with impaired hypoglycemia awareness had significantly lower plasma VEGF concentrations than those with normal awareness and that both factors, lower VEGF concentrations and impaired hypoglycemia awareness, were independently associated with the presence of coma.

A prominent risk factor for hypoglycemic coma in our series was insulin therapy in conjunction with oral hypoglycemic agents. This association may reflect the wellknown effect of antecedent hypoglycemia, which blunts the neurohormonal response to subsequent hypoglycemia. Our data also confirm that renal impairment is an independent risk factor for hypoglycemic coma [4, 5, 37]. We did not find that the use 
of benzodiazepines, $\beta$-blockers, renin-angiotensin system blockers, or NSAIDS was associated with severe hypoglycemia or hypoglycemic coma in either the univariate or multivariate analysis. The lack of association between these drugs and severe hypoglycemia is consistent with results in other studies $[31,38]$. It is likely that most such episodes are mild in comparison to the episodes associated with insulin and oral hypoglucemic agents and do not require hospitalization. However, in univariate analysis, it was found that polypharmacy was significantly associated with severe hypoglycemia and coma, also in line with other studies [4, 38].

Our study has some weaknesses and strengths. It is a single center study which might limit the applicability of our results. Plasma VEGF concentration is sensitive to influences of insulin and several stress hormones such as epinephrine, norepinehrine, or cortisol in circulating blood, and this fact might confound our present data. However, no significant association was found between plasma VEGF concentrations and these hormones, thus suggesting they do not have influence of them on VEGF concentrations. Our study cannot explain the mechanism underlying mechanism the observed plasma VEGF rise during severe hypoglycemia. Self-estimated impaired hypoglycemia awareness is based upon recall of the event therefore some kind of responder bias in the questionnaire survey cannot be ruled out. The strengths of the study include the range of available clinical and laboratory variables, the objective criteria for severe hypoglycemia or hypoglycemic coma, and the evaluation of counterregulatory hormones in response to acute severe hypoglycemia or coma and after restoration of normoglycemia, analyses which have not been done previously in studies of T2DM diabetic patients admitted for a severe hypoglycemic episode. Further studies are needed 
to validate our findings and clarify how often and to what extent the release of VEGF in response to severe hypoglycemic events is impaired.

In conclusion, our study demonstrates that VEGF and epinephrine responses to hypoglycemia are significantly decreased in T2DM patients with hypoglycemic coma as compared with that of non-coma patients. In the multivariate analysis, the development of coma was independently associated with a reduced magnitude of VEGF response. This observation indicates a potential influence of VEGF release on the maintenance of consciousness.

\section{Competing interests}

The authors declare that they have no competing interests.

\section{$\underline{\text { Authors' contributions }}$}

FA, MCM, EC, GA and AQ, contributed to acquisition of the data; FA, RC, RH, JR and CM participated in its design, coordination and statistical analysis; RC and $\mathrm{CM}$ performed the hormonal analyses; FA, and CM drafted the manuscript. All authors read and approved the final manuscript.

\section{Acknowledgements}

We wish to thank to Pilar González Gancedo, for their excellent technical assistance, and to Rosario Madero for statistical analysis. This work was supported by a grant from Plan Nacional I+D+I (SAF 2008-05347), and from Fundación Mutua Madrileña de Investigación Médica to Francisco Arnalich (PI 8945/ 2011) and to Carmen Montiel (research project 2008). 


\section{References}

[1] P.E. Cryer, Hypoglycemia, functional brain failure, and brain death, J Clin Invest 117 (2007), pp. 868-870

[2] S.A. Amiel, Hypoglycemia: from the laboratory to the clinic, Diabetes Care 32 (2009), pp. 1364-1371.

[3] H. Ben-Ami, P. Nagachandran, A. Mendelson, Y. Edoute, Drug-induced hypoglycemic coma in 102 diabetic patients. Arch Intern Med 159 (1999), pp. 281-284.

[4] R.I. Shorr, W.A. Ray, J.R. Daugherty, M.R. Griffin, Incidence and risk factors for serious hypoglycemia in older persons using insulin or sulfonylureas, Arch Intern Med 157 (1997), pp. 1681-86.

[5] G.P. Fadini, M. Rigato, A. Tiengo, A. Avogaro, Characteristics and mortality of type 2 diabetic patients hospitalized for severe iatrogenic hypoglycemia, Diab Res Clin Pract 84 (2009), pp. 267-272.

[6] G.K. Adler, I. Bonyhay, H. Failing, E. Waring, S. Dotson, R. Freeman, Antecedent hypoglycemia impairs autonomic cardiovascular function. Implications for rigorous glycemic control, Diabetes 58 (2009), pp. 360-366.

[7] S. Zoungas, A. Patel, J. Chalmers, B.E. de Galan, Q. Li, L. Billot, M. Woodward, T. Ninomiya, B. Neal, S. MacMahon, D.E. Grobbee, A.P. Kengne, M. Marre, S. Heller; ADVANCE Collaborative Group, Severe hypoglycemia and risks of vascular events and death, N Engl J Med 363 (2010),pp.1410-1418.

[8] F. Arnalich, M. Menéndez, V. Lagos, E. Ciria, A. Quesada, R. Codoceo, J.J. Vazquez, E. López-Collazo, C. Montiel, Prognostic value of cell-free plasma DNA in patients with cardiac arrest outside the hospital: an observational cohort study, Crit Care 14 (2010), pp. R47.

[9] N. Tesfaye, E.R. Seaquist, Neuroendocrine responses to hypoglycemia, Ann $N$ Y Acad Sci 1212 (2010), pp. 12-28

[10] P.E. Cryer, Mechanisms of hypoglycemia-associated autonomic failure and its component syndromes in diabetes, Diabetes 54 (2005), pp. 3592- 3660

[11] N. Ferrara, Vascular endothelial growth factor: basic science and clinical progress, Endocr Rev 25 (2004), pp. 581-611.

[12] H. Sone, B.K. Deo, A.K. Kumagai, Enhancement of glucose transport by vascular endothelial growth factor in retinal endothelial cells, Invest Ophtalmol Vis Sci 41 (2000), pp. 1878-1884 
[13] W Wang, M.J. Merrill, R.T. Borchardt, Vascular endothelial growth factor affects permeability of brain microvessel endothelial cells in vitro. Am J Physiol 271 (1996) (6 Pt1), pp C1973-C1980.

[14] S. Satake, M. Kuzuya, H. Miura, T. Asai, M.A. Ramos, M. Muraguchi, Y.

Ohmoto, A. Iguchi, Up-regulation of vascular endothelial growth factor in response to glucose deprivation, Biol Cell 90 (1998), p. 161-168.

[15] D. Dantz, J. Bewersdorf, B. Fruehwald-Schultes, W. Kern, W. Jelkmann, J. Born, H.L. Fehm, A. Peters , Vascular endothelial growth factor; a novel endocrine defensive response to hypoglycemia. J Clin Endocrinol Metab 87 (2002), pp. 835-840.

[16] Workgroup on Hypoglycemia, American Diabetes Association. Defining and reporting hypoglycemia: a report from the American Diabetes Association Workgroup on Hypoglycemia. Diabetes Care 28 (2005), pp. 1245-1249.

[17] L.A. Stevens, J. Coresh, T. Greene, A.S. Levey, Assessing kidney function measured and estimated glomerular filtration rate, N Engl J Med 354 (2006), pp. 2473-2483.

[18] A.E. Gold, K.M. MacLeod, B.M. Frier, Frequency of severe hypoglycemia in patients with type 1 diabetes with impaired awareness of hypoglycemia, Diabetes Care 17 (1994), pp. 697-703

[19] K.M. Oltmanns, H. Gehring, S. Rudolf, B. Schultes, C. Hackenberg, U. Schweiger, J. Born, H.L. Fehm, A. Peters, Acute hypoxia decreases plasma VEGF concentrations in healthy humans, Am J Physiol Endocrinol Metab 290 (2006), pp. E434-439.

[20] V. Merl, A. Peters, K.M. Oltmanns, W. Kern, C. Hubold, H.L. Fehm, J. Born, B. Schultes, Antecedent hypoglycemia attenuates vascular endothelial growth factor response to subsequent hypoglycaemia in healthy men, Diabet Med 22 (2005), pp. 1278-1281.

[21] K.M. Oltmanns, U.H. Melchert, H.G. Scholand-Engler, B. Schultes, U. Schweiger, A. Peters, Divergent effects of hyper- and hypoglycemia on circulating vascular endothelial growth factor in humans, Metab Clin Exp $\mathbf{5 7}$ (2008), pp. 90-94.

[22] P.L. Kristensen, T. Hoi-Hansen, F. Boomsma, U. Pedersen-Bjergaard, B. Thorsteinsson, Vascular endothelial growth factor during hypoglycemia in patients with type 1 diabetes mellitus: relation to cognitive function and reninangiotensin system activity, Metab Clin Exp 58 (2009), pp. 1430-1438. 
[23] N. Ferrara, W.J. Henzel, Pituitary follicular cells secrete a novel heparin-binding growth factor specific for vascular endothelial cells. Biochem Bipohys Res Commun 161 (1989), pp. 851-858.

[24] I. Gallard, M. Keramidas, P. Liakos, I. Vilgrain, J.J. Feige, D. Vittet, ACTHregulated expression of vascular endotelial growth factor in the adult bovine adrenal cortex: a possible role in the maintenance of the microvasculature. $J$ Cell Physiol 185 (2000), pp. 226-234.

[25] N. Ferrara, H.P. Gerber, J. LeCouter, The biology of VEGF and its receptors. Nat Med 9 (2003), p. 669-676.

[26] C.Y. Cheung, M. Singh, M.J. Ebanugh, R.A. Brace, Vascular endothelial growth factor gene expression in ovine placenta and fetal membranes. Am. J. Obstet. Gynecol. 267 (1995), pp 753-759.

[27] Z. Israelian, E. Szoke, J. Woerle, S. Bokhari, M. Schorr, D.C. Schwenke, P.E. Cryer, J.E. Gerich, C. Meyer, Multiple defects in counterregulation of hypoglycemia in modestly advanced type 2 diabetes mellitus, Metab Clin Exp 55 (2006), pp. 593-98.

[28] M.R. Burge, T.A. Sobhy, C.R. Qualls, D.S. Schade, Effect of short-term glucose control on glycemic thresholds for epinephrine and hypoglycemic symptoms. $J$ Clin Endocrinol Metabol 86 (2001), pp. 5471-5478.

[29] S.N. Davis, S. Mann, V.J. Briscoe, A.C. Ertl, D.B. Tate, Effects of intensive therapy and antecedent hypoglycemia on counterregulatory responses to hypoglycemia in type 2 diabetes, Diabetes 58 (2009), pp. 701-709.

[30] A.M. Arbelaez, W.J. Powers, T.O. Videen, J.L. Price, P.E. Cryer, Attenuation of counterregulatory responses to recurrent hypoglycemia by active thalamic inhibition: a mechanism for hypoglycemia-associated autonomic failure. Diabetes 57 (2008), pp. 470-475.

[31] J.E. Schopman, J. Geddes, B.M. Frier, Prevalence of impaired awareness of hypoglycemia and frequency of hypoglycemia in insulin-treated type-2 diabetes. Diab Res Clin Pract 87 (2010), pp. 64-68.

[32] I. Cranston, L.J. Reed, P.K. Marsden, A.S. Amiel, Changes in regional brain $18 \mathrm{~F}$-fluordeoxyglucose uptake at hypoglycemia in type 1 diabetic men associated with hypoglycemia unawareness and counterregulatory failure, Diabetes 50 (2001), pp. 2329-2336.

[33] O. Chan, H. Cheng, R. Herzog, D. Czyzyk, W. Zhu, A. Wang, R.J. McCrimmon, M.R. Seashore, R.S. Sherwin, Increased GABAergic tone in the 
ventromedial hypothalamus contributes to suppression of counterregulatory responses after antecedent hypoglycemia, Diabetes 57 (2008), pp. 1363-1370.

[34] A.K. Kumagai, Y.S. Kang, R.J. Boado, W.M. Partridge, Upregulation of bloodbrain barrier GLUT1 glucose transporter protein and mRNA in experimental chronic hypoglycemia, Diabetes 44 (1995), pp. 1399-1404.

[35] A.B. Criego, I. Tkac, A. Kumar, W. Thomas, R. Gruetter, E.R. Seaquist, Brain glucose concentrations in patients with type 1 diabetes and hypoglycemia unawareness. J Neurosci Res 79 (2005), pp. 42-47.

[36] P.G. Henry, A.B. Criego, A. Kumar, E.R. Seaquist, Measurement of cerebral oxidative glucose consumption in patients with type 1 diabetes mellitus and hypoglycemia unawareness using ${ }^{(13)} \mathrm{C}$ nuclear magnetic resonance spectroscopy, Metabolism 59 (2010), pp. 100-106.

[37] K. Akram, U. Pedersen-Bjergaard, B. Carstensen, K. Borch-Johnsen, B. Thorsteinsson, Frequency and risk factors of severe hypoglycemia in insulintreated Type 2 diabetes: a cross-sectional survey. Diabet Med 23 (2006), pp. 750-756.

[38] T.M.E. Davis, S.G.A. Brown, I.G. Jacobs, M. Bulsara, D.G. Bruce, W.A. Davis, Determinants of severe hypoglycemia complicating type 2 diabetes: The Fremantile Diabetes Study. J Clin Endocrinol Metab 95 (2010), pp. 2240-2247. 
Table 1: Descriptive characteristics of the study cohort

\begin{tabular}{|c|c|c|c|}
\hline & \multicolumn{2}{|l|}{ Age } & $71(66-75)$ \\
\hline & \multicolumn{2}{|l|}{ Female } & 79 (58.5) \\
\hline & \multicolumn{2}{|l|}{ Duration of diabetes } & $11(6-15)$ \\
\hline & \multicolumn{2}{|l|}{$\begin{array}{l}\text { Previous self-reported (mild) } \\
\text { hypoglycemia }\end{array}$} & $72(53.3)$ \\
\hline & \multicolumn{2}{|l|}{ Antecedent severe hypoglycemia } & $28(20.7)$ \\
\hline & \multicolumn{2}{|l|}{ Impaired hypoglycemia awareness } & 18 (13.3) \\
\hline & \multicolumn{2}{|l|}{ Duration of hypoglycemia, $\mathrm{hr}$} & $5.2(2.9-8.1)$ \\
\hline \multirow[t]{4}{*}{ Underlying cause of hypoglycemia } & \multicolumn{2}{|l|}{ Low carbohydrate intake } & $71(52.6)$ \\
\hline & \multicolumn{2}{|l|}{ Acute bacterial infection } & 20 (14.8) \\
\hline & \multicolumn{2}{|c|}{$\begin{array}{l}\text { Errors in the administration of insulin, } \\
\text { or other medications }\end{array}$} & $13(9.6)$ \\
\hline & \multicolumn{2}{|l|}{ Undetermined } & $31(23.0)$ \\
\hline \multirow[t]{5}{*}{ Comorbidity } & \multicolumn{2}{|l|}{ Hypertension } & $91(67.4)$ \\
\hline & \multicolumn{2}{|l|}{ Obesity } & 59 (43.7) \\
\hline & \multicolumn{2}{|l|}{ Dyslipidemia } & $38(28.1)$ \\
\hline & \multicolumn{2}{|l|}{ Heart failure } & $26(19.2)$ \\
\hline & \multicolumn{2}{|l|}{ COPD/emphysema } & $19(14.1)$ \\
\hline \multirow[t]{3}{*}{ Diabetic complications } & \multicolumn{2}{|l|}{ Coronary artery dissease } & $54(40.0)$ \\
\hline & \multicolumn{2}{|l|}{ Peripheral artery disease } & 25 (18.9) \\
\hline & \multicolumn{2}{|l|}{ Retinopathy } & $22(16.2)$ \\
\hline \multirow[t]{4}{*}{ Diabetes therapy } & \multicolumn{2}{|l|}{ Insulin alone ( $\geq 2$ injections daily) } & $52(38.5)$ \\
\hline & \multicolumn{2}{|l|}{ Insulin and metformin } & $26(19.3)$ \\
\hline & \multicolumn{2}{|l|}{ Insulin, metformin and sulfonylurea } & $13(9.6)$ \\
\hline & $\begin{array}{l}\text { Sulfonilurea alone or in combinat } \\
\text { with metformin }\end{array}$ & & $44(32.6)$ \\
\hline Medications: hypoglycemia- & Benzodiacepines & & $24(17.8)$ \\
\hline potentiating drugs. & Beta-blockers & & $38(28.1)$ \\
\hline & Renin-Angotensin system blocker & & $61(45.2)$ \\
\hline & Diuretics & & $21(15.6)$ \\
\hline Medications: other drugs & NSAIDs & & $32(23.7)$ \\
\hline Polypharmacy & $\geq 5$ medications & & 56 (41.5) \\
\hline Clinical outcome & Lose of consciousness $\geq 30 \mathrm{~min}$ & & $32(23.7)$ \\
\hline LABORATORY VALUES & $\begin{array}{l}\text { At admission to the ED } \\
(n=135)\end{array}$ & & $\begin{array}{l}\text { month follow-up } \\
n=135)\end{array}$ \\
\hline First blood glucose (mg/dl) & $39(34-45)$ & 122 & $110-145) * *$ \\
\hline $\operatorname{HbA1C}(\%)$ & $7.0(6.6-7.5)$ & 7.4 & $0-7.8)$ \\
\hline White blood cells (cells/ $\mu \mathrm{l})$ & $12.6(9.5-13.2)$ & 7.3 & $2-8.4)$ \\
\hline Serum creatinine $(\mathrm{mg} / \mathrm{dl})$ & $1.40(1.18-1.81)$ & 1.45 & $1.15-1.75)$ \\
\hline Arterial oxygen saturation $\left(\mathrm{Sat}_{2}\right)(\%)$ & $97.2(96.1-99.2)$ & 97.8 & $96.0-99.1)$ \\
\hline Estimated GFR $\left(\mathrm{ml} / \mathrm{min} / 1.73 \mathrm{~m}^{2}\right)$ & $63.5(58.3-68.4)$ & 63.7 & $57.5-68.1)$ \\
\hline VEGF (pg/ml) & $221(115-386)$ & 51( & $-65)^{* *}$ \\
\hline Epinephrine (pg/ml) & $392(190-582)$ & 34 & $1-58)^{* * *}$ \\
\hline Norepinephrine (pg(ml) & $571(470-688)$ & 108 & $9-155)^{* *}$ \\
\hline Cortisol $(\mu \mathrm{g} / \mathrm{l})$ & $10.7(9.5-12.1)$ & 9.4 & $5-10.9)^{*}$ \\
\hline Growth hormone (ng/ml) & $6.2(3.2-10.8)$ & 2.1 & $-6-.6 .4)^{* *}$ \\
\hline
\end{tabular}


Table 2: Comparisons of factors associated with hypoglycemic coma.

\begin{tabular}{|c|c|c|c|}
\hline & $\begin{array}{l}\text { Coma } \\
(\mathrm{n}=32)\end{array}$ & $\begin{array}{c}\text { Non-Coma } \\
(\mathrm{n}=103)\end{array}$ & $\mathrm{p}$ \\
\hline Age, years & $72(69-75)$ & $70(68-77)$ & NS \\
\hline Gender, female, & $17(53.1)$ & $62(60.2)$ & NS \\
\hline Duration of diabetes & $13(9-17)$ & $9(5-13)$ & NS \\
\hline Self-reported mild hypoglycemia & $22(68.7)$ & $50(48.5)$ & NS \\
\hline Antecedent severe hypoglycemia & $20(62.5)$ & $8(7.8)$ & $<0.01$ \\
\hline Impaired hypoglycemia awareness & $15(46.9)$ & $3(2.9)$ & $<0.01$ \\
\hline Duration of hypoglycemia, $\mathrm{hr}$ & $7.1(5.5-8.1)$ & $4.1(2.9-5.2)$ & $<0.01$ \\
\hline Underlying cause of hypoglycemia & & & \\
\hline Low carbohydrate intake & $20(62.5)$ & $51(49.5)$ & NS \\
\hline Acute bacterial infections & $5(15.6)$ & $12(11.6)$ & NS \\
\hline Undetermined & $8(25.0)$ & $23(22.3)$ & NS \\
\hline Diabetic complications & & & \\
\hline Coronary artery disease & $15(46.8)$ & $39(37.9)$ & NS \\
\hline Peripheral artery disease & $7(21.9)$ & $18(17.5)$ & NS \\
\hline Retinopathy & $9(28.1)$ & $17(16.5)$ & NS \\
\hline Diabetes therapy & & & \\
\hline Insulin alone ( $\geq 2$ injections daily) & $21(65.6)$ & $31(30.1)$ & $<0.01$ \\
\hline Insulin and oral hypoglycemic agents & $6(18.7)$ & $33(32.0)$ & NS \\
\hline SU alone or SU plus metformin & $5(15.6)$ & $38(36.8)$ & NS \\
\hline Medications & & & \\
\hline Benzodiacepines & $7(21.9)$ & $17(16.5)$ & NS \\
\hline Beta-blockers & $9(28.1)$ & $33(32.0)$ & NS \\
\hline Renin-Angotensin system blockers & $17(53.1)$ & $44(42.7)$ & NS \\
\hline Diuretics & $5(15.6)$ & $16(15.5)$ & NS \\
\hline NSAIDs & $8(25.0)$ & $24(23.3)$ & NS \\
\hline Polypharmacy ( $\geq 5$ medications) & $20(62.5)$ & $36(35.0)$ & $<0.05$ \\
\hline Laboratory values & & & \\
\hline First blood glucose $(\mathrm{mg} / \mathrm{dl})$ & $36(32-41)$ & $42(39-45)$ & $<0.05$ \\
\hline 30-min blood glucose & $65(57-74)$ & $74(66-80)$ & NS \\
\hline $\operatorname{HbA1C}(\%)$ & $7.2(6.8-7.5)$ & $7.4(7.2-7.8)$ & NS \\
\hline White blood cells (cells/ $\mu \mathrm{l})$ & $13.5(11.3-14.4)$ & $12.1(11.5-12.8)$ & NS \\
\hline Serum creatinine $(\mathrm{mg} / \mathrm{dl})$ & $1.45(1.20-1.81)$ & $1.35(1.18-1.74)$ & NS \\
\hline Estimated GFR $\left(\mathrm{ml} / \mathrm{min} / 1.73 \mathrm{~m}^{2}\right)$ & $62.4(58.3-65.2)$ & $65.3(62.7-69.4)$ & $<0.05$ \\
\hline Basal VEGF (pg/ml) & $82(70-135)$ & $254(134-386)$ & $<0.01$ \\
\hline 30-min VEGF (pg/ml) & $94(70-144)$ & $502(305-628)$ & $<0.01$ \\
\hline Basal epinephrine (pg/ml) & $251(180-314)$ & $484(360-582)$ & $<0.01$ \\
\hline 30-min epinephrine & $274(185-434)$ & $562(350-730)$ & NS \\
\hline Basal norepinephrine (pg/ml) & $522(470-735)$ & $595(490-688)$ & NS \\
\hline 30-min nor epinephrine & $691(612-740)$ & $635(515-720)$ & NS \\
\hline Basal cortisol $(\mu \mathrm{g} / \mathrm{ml})$ & $10.9(9.7-12.1)$ & $10.6(9.5-11.9)$ & NS \\
\hline 30-min cortisol & $10.5(9.4-11.7)$ & $10.8(9.8-12.2)$ & NS \\
\hline Growth hormone (ng/ml) & $6.4(3.2-11.4)$ & $6.1(3.1-10.8)$ & NS \\
\hline 30-min growth hormone & $6.7(3.5-11.2)$ & $6.6(4.2-11.0)$ & NS \\
\hline
\end{tabular}

Data are median (IQR) or number (\%). SU: sulfonylurea; NSAIDs: non-steroidal antiinflammatory agents. 
Table 3: Laboratory values of patients subgroup with impaired hypoglycemia awareness

\begin{tabular}{|l|l|l|}
\hline & $\begin{array}{l}\text { IAH patients } \\
(\mathrm{n}=18)\end{array}$ & $\begin{array}{l}\text { Non-IAH patients } \\
(\mathrm{n}=117)\end{array}$ \\
\hline First blood glucose $(\mathrm{mg} / \mathrm{dl})$ & $38(34-44)$ & $40(33-45)$ \\
\hline HbA1C $(\%)$ & $6.9(6.5-8.0)$ & $7.2(7.3-7.9)$ \\
\hline White blood cells $(\mathrm{cell} / \mathrm{s} / \mathrm{l})$ & $12.4(9.3-13.7)$ & $11.8(10.1-13.3)$ \\
\hline Serum creatinine $(\mathrm{mg} / \mathrm{dl})$ & $1.40(1.18-1.85)$ & $1.43(1.16-1.79)$ \\
\hline Estimated GFR $\left(\mathrm{ml} / \mathrm{min} / 1.73 \mathrm{~m}^{2}\right)$ & $63.5(57.8-.69 .3)$ & $64.1(58.1-68.4)$ \\
\hline VEGF $(\mathrm{pg} / \mathrm{ml})$ & $86(72-140)$ & $250(138-386)^{* *}$ \\
\hline Epinephrine $(\mathrm{pg} / \mathrm{ml})$ & $286(190-454)$ & $475(306-618)^{*}$ \\
\hline Norepinephrine $(\mathrm{pg}(\mathrm{ml})$ & $564(471-680)$ & $582(496-735)$ \\
\hline Cortisol $(\mu \mathrm{g} / \mathrm{l})$ & $10.8(9.7-11.7)$ & $10.7(9.6-12.2)$ \\
\hline Growth hormone $(\mathrm{pg} / \mathrm{ml})$ & $6.0(3.7-10.9)$ & $6.5(3.1-10.8)$ \\
\hline
\end{tabular}

IHA: Impaired hypoglycemia awareness

Data are median (IQR) or number (\%)

P values: ${ }^{*} p<0.05 ;{ }^{* *} p<0.01$ 


\begin{tabular}{|l|c|c|c|}
\hline \multirow{2}{*}{} & \multicolumn{2}{|c|}{ Hypoglycemic coma } \\
\cline { 2 - 4 } & $\begin{array}{c}\text { Adjusted } \\
\text { OR }\end{array}$ & $95 \%$ CI & P-value \\
\hline Age (per 1 year increase) & 1.04 & $0.95-1.06$ & 0.344 \\
\hline Male sex & 0.96 & $0.62-1.87$ & 0.635 \\
\hline $\begin{array}{l}\text { Admission VGEF (per each } \\
\text { increase of 50 pg/ml) }\end{array}$ & 0.68 & $0.51-0.93$ & $<0.001$ \\
\hline $\begin{array}{l}\text { Multidose insulin therapy } \\
\text { injections daily) }\end{array}$ & 2.48 & $1.68-6.12$ & $<0.001$ \\
\hline $\begin{array}{l}\text { Antecedent severe } \\
\text { hypoglycemia }\end{array}$ & 1.86 & $1.38-5.42$ & $<0.01$ \\
\hline $\begin{array}{l}\text { Impaired renal function } \\
\text { ( eGFR < 60 ml/min/1.73 } \mathrm{m}^{2} \text { ) }\end{array}$ & 1.73 & $1.10-4.28$ & $<0.01$ \\
\hline $\begin{array}{l}\text { Impaired hypoglycemia } \\
\text { awareness }\end{array}$ & 1.21 & $1.10-3.85$ & $<0.01$ \\
\hline
\end{tabular}

Table 4: Multivariate logistic regression analysis of risk factors associated with hypoglycemic coma. 